Pawan Pandey, Somil Agrawal, and J. Uma Maheswari(2018). "Optimizing flow process through synchronization of cycle time." In: Proc. $26^{\text {th }}$ Annual Conference of the International. Group for Lean Construction (IGLC), Chennai, India, pp. 786-796. DOI: doi.org/10.24928/2018/0497. Available at: www.iglc.net.

\title{
OPTIMIZING FLOW PROCESS THROUGH SYNCHRONISATION OF CYCLE TIME
}

\author{
Pawan Pandey ${ }^{1}$, Somil Agrawal ${ }^{2}$, and J. Uma Maheswari ${ }^{3}$
}

\begin{abstract}
Construction projects can be modelled, using TFV theory of lean construction, as combination of main activity network that are primarily transformations and feeding flow processes which supply input material to main activities. These feeding processes may include one or more sub-processes/ and operations with varying cycle time $(\mathrm{C} / \mathrm{T})$. The lack of synchronization between these sub processes/ operations results into construction bottlenecks which delay the execution of main activities. Mechanization of few processes/ sub-processes or operations in isolation create large variation in cycle time and shifts the location of bottlenecks. Thus, limited benefits accrue from mechanization, automation, etc.

The present study proposes a framework to locate the bottlenecks through hierarchical process analysis and discrete event simulation. These bottlenecks can be eliminated through modifying cycle time of selected sub process /operation by changing resources allocation and by eliminating waste with the ultimate aim to enhance overall productivity. The proposed framework is demonstrated utilizing data from an automated railway track construction project. The substantial improvement in construction productivity was observed after synchronization of cycle time.
\end{abstract}

\section{KEYWORDS}

Lean construction, cycle time synchronisation, construction bottlenecks, discrete event simulation, automated railway track laying.

\section{INTRODUCTION}

Construction project are complex, executed in a dynamic environment and broken into work packages (WPs) for efficient management. These WPs generally have one main conversion activity supported by a set of sub-processes/ operations to produce measurable output. These main activities are logically sequenced against logic and resource constraint for efficient execution. Often these WPs are assigned to different process heads whose focus is more on ensuring high local productivity than overall project performance. Often varying degree of mechanization are introduced at different level in view of

\footnotetext{
Research Scholar, Department of Civil Engineering, IIT Delhi, India, pvnengr@gmail.com

Post Graduate Student, Department of Civil Engineering, IIT Delhi, India, somil27@iitd.ac.in

Assistant Professor, Department of Civil Engineering, IIT Delhi, India, uma.iit@ gmail.com
} 
competing needs of different process heads, special conditions of contract for quality assurance, etc.

In one of the ongoing railway track laying project in India, automated pre-stressed sleeper manufacturing was adopted to expedite track laying. However, daily progress remained slow (i.e. $200 \mathrm{~m}$ per day) since because track laying was being done manually. The sleeper casting beds remained idle for prolonged period due to low demand from track laying crew. The introduction of automated New Track Construction (NTC) machine was then introduced to speedup track laying process which had daily capacity to lay $1.5 \mathrm{~km}$ but the achieved progress was only $1.15 \mathrm{~km}$ as sleeper production could not match the desired progress. The delays were random and unpredictable at different activity level. The variations in $\mathrm{C} / \mathrm{T}$ amongst the sub processes (i.e. sleeper production $\mathrm{C} / \mathrm{T}$ was $47.3 \mathrm{hrs}$ and track laying C/T using NTC was $10 \mathrm{hrs}$ for $1.5 \mathrm{~km}$ track work) and operations within these feeding processes were causing construction bottlenecks. These bottlenecks not only reduced construction productive but also delayed the entire project. It is apparent that mechanization of few processes/ sub-processes or operations in isolation, yields limited benefits and shifts the location of bottlenecks. Therefore, the present study is aimed to develop a framework to enhance overall construction productivity by balancing the flow through identifying and eliminating of likely construction bottlenecks.

\section{RESEARCH BACKGROUND}

The theoretical understanding of construction have evolved progressively from transformations model to flow model and then to TFV (i.e., Transformation, Flow and Value) theory for lean construction Koskela (2000). The TFV theory assumes construction project as combination of transformation and flow activities which progressively add value to meet customers need. Diekmann et al. (2004) through a set of case studies highlighted the need to eliminate/ optimize flow activities which consumed almost $70 \%$ of the time and resource. Despite waste reduction, variability in construction flow process is inevitable due to variation $\mathrm{C} / \mathrm{T}$ of its components. This variability leads to penalties i.e.,need for buffers and sub optimal resource utilization (Hopp and Spearman 2001). Despite known benefits, few researchers have attempted to reduce flow variability (Bertelsen et al. 2006). Ballard and Tommelin (1999) proposed tools and techniques for continuous flow process (CFP).'Last Planner' system minimizes in flow variations through commitment based execution planning (Ballard and Howell 1994). Binninger et al. (2016) investigated applicability of work process levelling tools to achieve rhythmic production. Pawan et al., (2017) presented a case study to balance flow process using multiple crew and crew multi-tasking.

Since construction project are complex (Oglesby 1989) and involve plethora of flow processes (Bertelsen et al. 2006), all project components cannot be structured in CFPs (Ballard and Tommelin 1999). The situation becomes even more complex when part mechanisation is introduced in a process without careful planning and disturbs existing flow balance. Thus, a framework is needed to systematically analyse the existing flow process, identify likely bottlenecks and indicate the extent to which adjustment in $\mathrm{C} / \mathrm{T}$ is 
needed for rhythmic production. The use of charts and tables may be adequate for simple processes. However, discrete event simulation (Alzraiee et al. 2015) will be needed for complex projects. Removal of these bottlenecks in successive steps during planning and scheduling stage can improve project performance in cost effective manner.

\section{RESEARCH METHODOLOGY}

Exhaustive literature survey was carried out to understand theoretical framework of construction project and root cause behind formation of construction bottlenecks. TFV theory of lean construction and continuous flow process (CFP) design concept are utilized to formulate the research hypothesis "synchronization of $C / T$ of interconnected sub process/ operation in process will enhance the process productivity by minimizing construction bottlenecks".

As shown in Figure 1, the methodology involved developing solution framework and testing of the enunciated hypothesis developed using case study approach. Multiple techniques were used to collect the data from two sites of an ongoing project over a period of one month duration and Extend Sim was used as DES (i.e discrete event simulation) tool to identify the bottlenecks along with preparation of material/ crew flow. Although the study was carefully designed to minimize the chances of misrepresentation, there are limitations on generalizing findings from a single case study (Stake 1995).
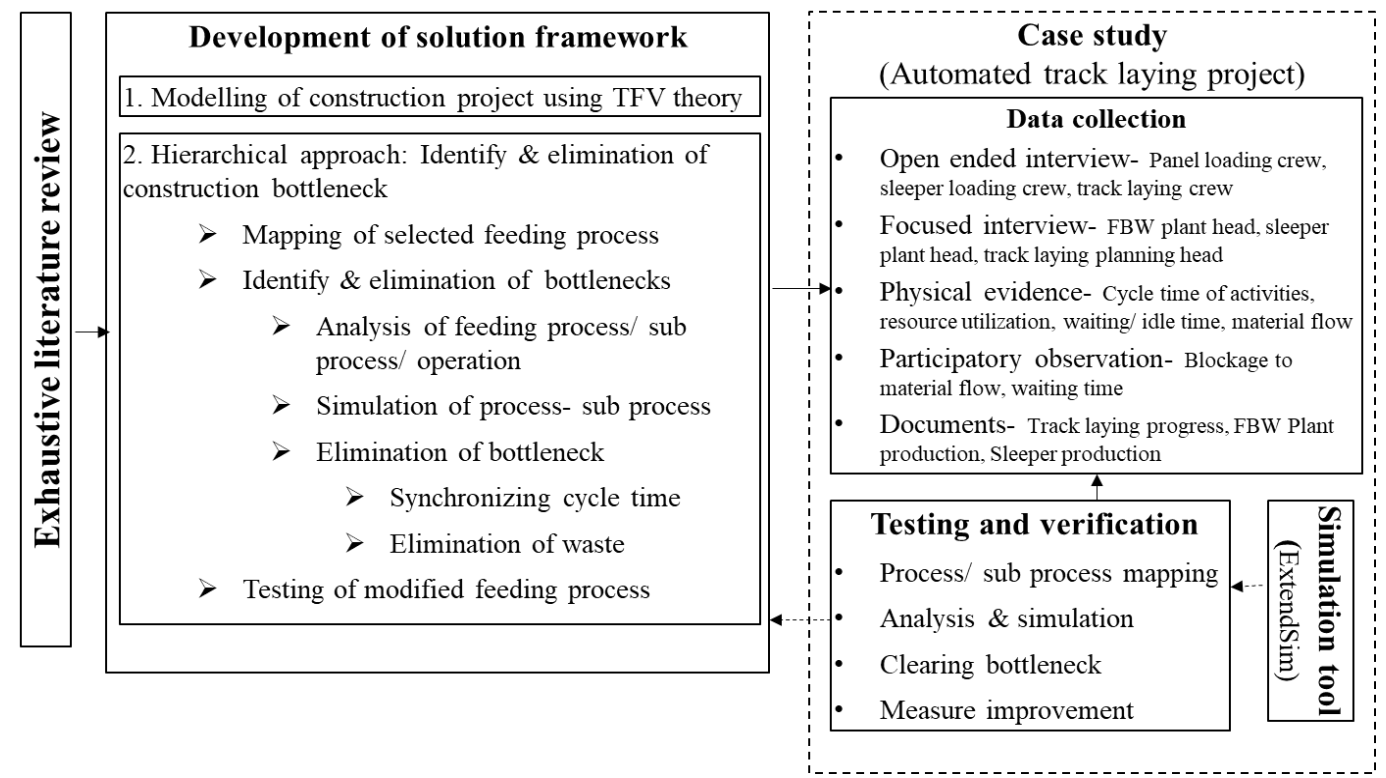

Figure 1: Research Methodology

\section{SOLUTION FRAMEWORK}

A construction project can be modelled as combination of main activity network and feeding processes (Bertelsen et al. 2006) as shown in Figure 2. These feeding processes consist of linearly connected (i.e., end to start relation) sub processes/ operations. In the present study 'operation' is considered asset of tasks performed by a crew (i.e 
combination of man and machine) which cannot be broken further and a sub process is a combination of more than one operation with identifiable input and output.

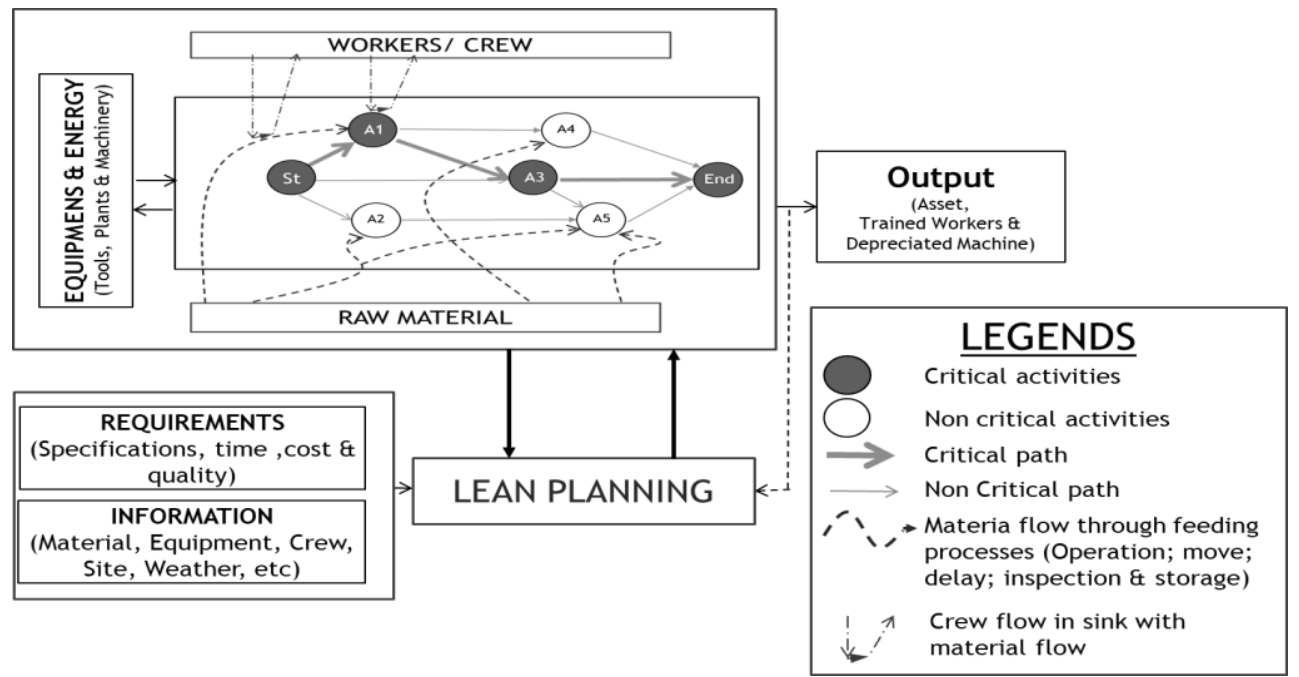

Figure 1: Model of Construction Project (Koskela 2000; Bertelsen et al. 2006).

Ideally material should flow continuously through each of its sub-processes and operation (Ballard and Tommelien 1999) which means each sub-process/ operation should process same quantity of material in a unit of time (i.e hour, shift, day, etc). The variation in $\mathrm{C} / \mathrm{T}$ creates bottlenecks as some sub process/ operation would not be able to match the material processing rate of their predecessors and/or successors. A flow diagram for optimization of flow process is shownas Figure 3.

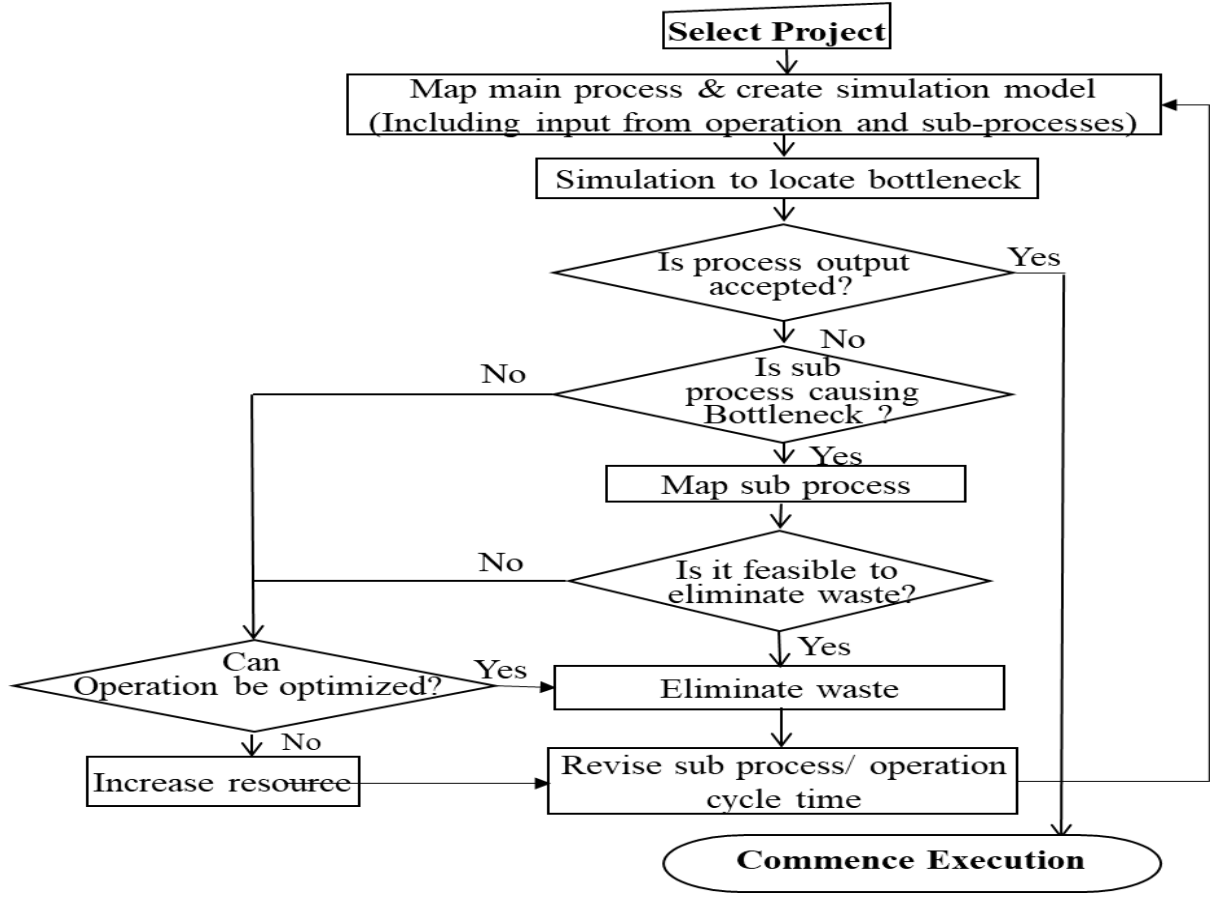


Figure 3: Flowchart to Clear Bottlenecks

The sub process/operation with little or nil idle time (i.e crew waiting for input material from downstream) located just before sub-process or operation with high idle time is the place where bottleneck is being formed. Since construction projects are complex involving multiple feeding processes with several sub processes and operations, complete synchronization of $\mathrm{C} / \mathrm{T}$ is not feasible. Hence, it will be appropriate to select key feeding process, map all sub processes/ operations and keep on optimizing hierarchically till desired productivity is achieved through synchronization of C/T. The $\mathrm{C} / \mathrm{T}$ can be modified either by additional allocation of resource and/ or elimination of waste using lean principles. The process involves data collection, process mapping, identification and elimination of bottlenecks progressively from feeding process to sub process and then to operations levels.

\section{CASE STUDY}

\section{PROJECT DESCRIPTION}

The proposed study was performed to identify the cause behind low productivity of NTC (i.e $1.15 \mathrm{~km} /$ day instead of $1.5 \mathrm{~km}$ /day) employed in a green field railway track laying project in India. The scope of work involved $626 \mathrm{~km}$ track laying which was divided into two sectors; 1) from 0 to $340 \mathrm{Km}$; 2) 340 to $626 \mathrm{~km}$. Base depot of Sector I was located at $107 \mathrm{~km}$ and Sector II base depot was located at $436 \mathrm{~km}$. The track laying process involves welding of $25 \mathrm{~m}$ long rails in flash butt welding (FBW) plant to form $250 \mathrm{~m}$ long rail panels which are then loaded in the rake (i.e group of rail cars) using a gantry set-up. The concrete sleepers are mass produced using semi-automated system. After loading rail panels, rakeis moved to sleeper plan wherein sleepers are loaded using gantry setup. This loaded rake is hauled from the Depot to the NTC location by a locomotive. The loaded rake is attached to the rear of NTC machine and the NTC machine starts placing the sleepers at predetermined spacing and the rail panels on top of it. After the sleepers, rail panels, clips etc. are exhausted, the empty rake is hauled back to the depot by the locomotive and the cycle is repeated. The NTC typically starts laying track from the depot and as it moves away from the depot, the distance between the depot and NTC location keeps on increasing. This increases overall $\mathrm{C} / \mathrm{T}$ of track laying and reduces rate of progress.

\section{DATA COLLECTION AND ANALYSIS}

\section{Mapping of Track Construction Process}

The NTC machine has capacity to lay $1.5 \mathrm{~km}$ track of approximately 10 hours. However, productivity of NTC was $30 \mathrm{~km}$ against planned progress of $40.5 \mathrm{~km}$ (assuming 31 days in a month). Since, there was no breakdown of NTC machine, lower productivity is attributed to some other sub process or operation. The railway track construction can be modelled as one pull activity (i.e track laying using NTC) and supply of input material to the NTC as feeding process (Figure 2). The sub processes and operations involved in this 
feeding process with their planned and actual $\mathrm{C} / \mathrm{T}$ is illustrated through graph in Figure 4. As seen in the graph, sleeper production, sleeper loading and travellingof rake to NTC have $\mathrm{C} / \mathrm{T}$ higher than planned $\mathrm{C} / \mathrm{T}$. Hence, these selected sub processes would require detailed analysis.
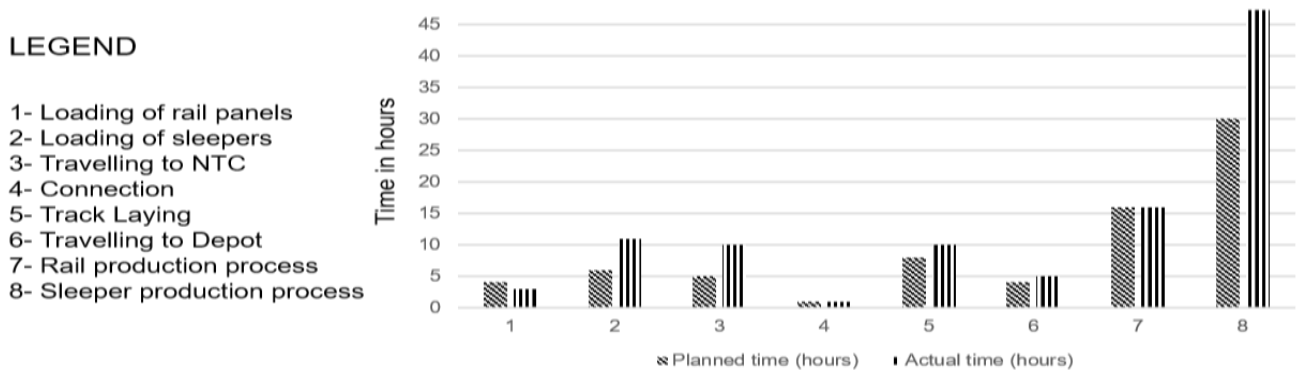

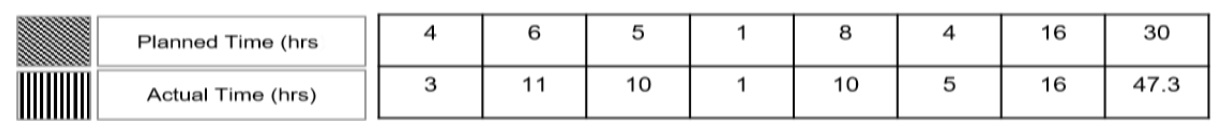

Figure 4: Railway Track Construction Process

\section{Flow Process Analysis}

The summary of the entire process with typicaltravelling time of rake is shownasFigure 5 . In addition material flow chart was made to identify interdependence between various sub process/ operations in addition to identification and elimination of waste. The analysis revealed that rail production (B sub process) is fairly efficient. The loading of sleepers in the rake (A2 operation) was inefficient and affected by frequent breakdown of gantry. The hauling of rake to NTC took long time due to variable hauling distance (Figure 5) which required accurate identification NTC position and coordination between NTC crew loco-operators. 


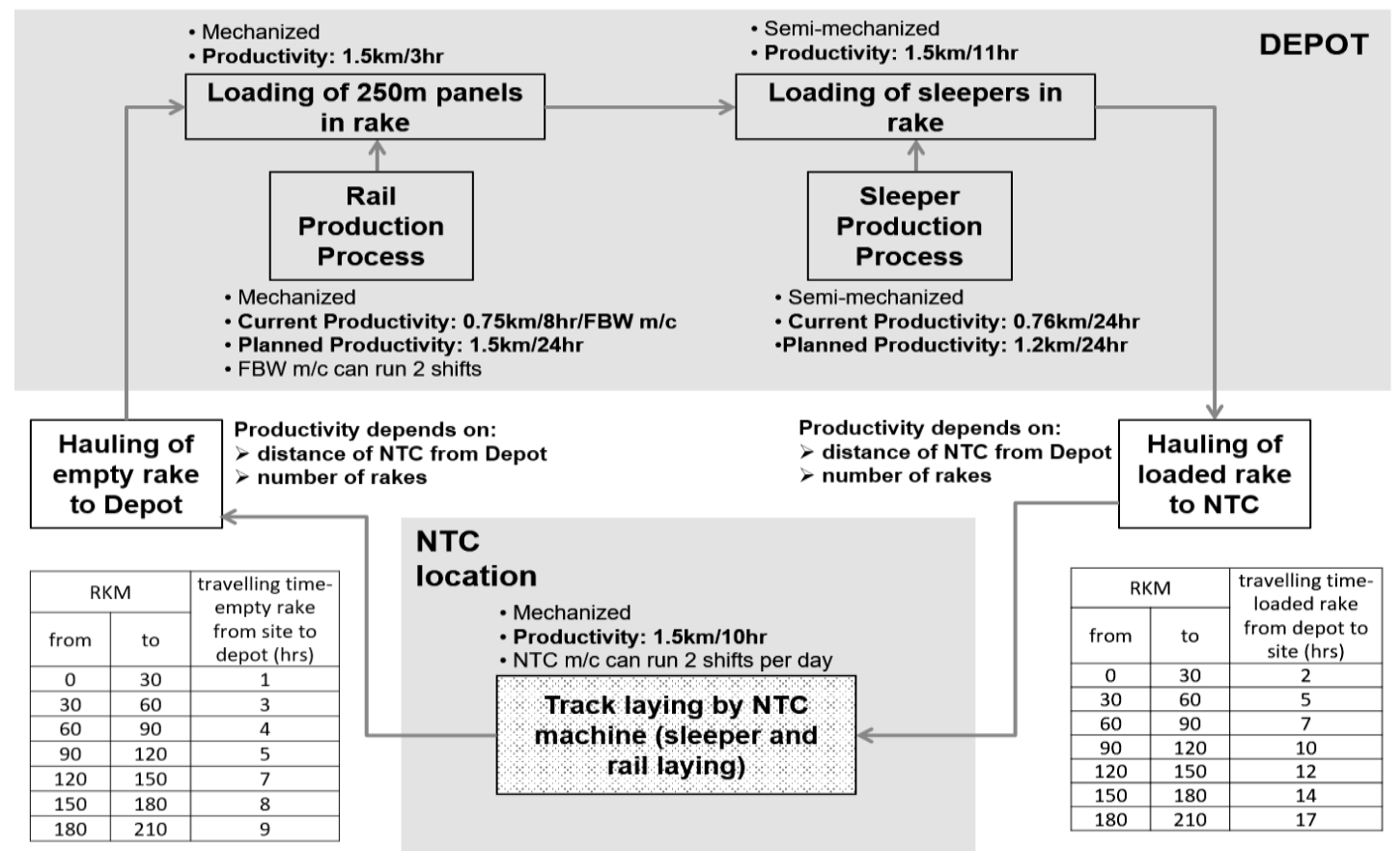

Figure 5: Flow of Railway Track Construction Process

Thus, use of GPS based tracking system was recommended. As seen in Figure 4, sleeper production sub process is the slowest which took almost 2 days to produce 2500 sleepers required for $1.5 \mathrm{~km}$.

The study revealed that use of 2 gantrycan reduce loading time from $11 \mathrm{hrs}$ to $5 \mathrm{hrs}$ (i.e. one gantry loads 20 sleepers in 5 min; 2500 sleepers will require $10 \mathrm{hrs} 25 \mathrm{~min}$ ). In case of breakdown one gantry will also work as reserve for the other. The use two FBW crew can reduce the C/T from $16 \mathrm{hrs}$ to $8 \mathrm{hrs}$. The use of GPS based system and better communication system can save approximately 2 hours in hauling of rake to NTC. However, sleeper production system would require deeper analysis as there are multiple sub processes/ operations are involved.

\section{Mapping of Sleeper Production Sub-Process}

The sleepers are produced by the long-line method of sleeper production where each bed has 400 moulds for casting the sleepers. The number of beds is a variable and depends on the resources available and the production of sleepers needed. The sequence of activities in sleeper production process and resource required are; 1) Cleaning the beds and insert fixing- one crew with cleaning tools; 2) HTS Wire Pulling-one crew with baffle machine; 3) HTS Wire Tensioning- one crew with tension gun; 4) Concreting and Baffle removingone crew for concreting and baffle machine crew; 5) Steam Curing- nil; 6) Wire Cutting and De-moulding- one crew each for cutting and de-moulding. In addition tractor mounted buckets are required for transporting concrete from batching plant. Since, sleeper production is done in parallel on multiple beds, managing flow of construction teams, machinery and material becomes crucial. 
As seen in Table 1, the $\mathrm{C} / \mathrm{T}$ for three operations (i.e Cleaning and insert fixing; HTS wire pulling; and Initial tensioning) are in excess of planned C/T. Also the waiting time is to the tune of around 5 hours which needs to be eliminated by managing the flow of crew and machinery. The material flow is also getting constricted during the shifting of sleepers to curing tank.

Table 1: Sleeper Production Process Analysis

\begin{tabular}{|c|c|c|c|c|c|c|c|c|}
\hline \multirow[t]{2}{*}{ SN Activities } & \multirow{2}{*}{$\begin{array}{l}\text { Men } \\
\text { Nos }\end{array}$} & \multirow{2}{*}{$\begin{array}{l}\text { Planned } \\
\text { (hh:mm) }\end{array}$} & \multicolumn{5}{|c|}{ Average (hh:mm) } & \multirow[b]{2}{*}{ Month } \\
\hline & & & W-1 & W-2 & W-3 & W-4 & W-5 & \\
\hline 1 Cleaning \& Insert Fixing & 8 & $1: 30$ & $4: 43$ & $6: 35$ & $5: 06$ & $5: 00$ & $5: 03$ & $5: 17$ \\
\hline 2 HTS Wire Pulling & 8 & $2: 00$ & $4: 19$ & $5: 01$ & $4: 53$ & $4: 28$ & $4: 50$ & $4: 42$ \\
\hline 3 Initial Tensioning & 4 & $1: 30$ & $3: 48$ & $3: 39$ & $4: 10$ & $3: 30$ & $3: 52$ & $3: 48$ \\
\hline 4 Final Tensioning & 1 & 0.30 & $0: 20$ & $0: 30$ & $0: 22$ & $0: 46$ & $0: 24$ & $0: 28$ \\
\hline $\begin{array}{l}5 \text { Concreting \& Baffle } \\
\text { Removing }\end{array}$ & 14 & $3: 30$ & 4:08 & $5: 45$ & 4:00 & $3: 59$ & $3: 52$ & $4: 21$ \\
\hline 6 Steam Curing & 2 & $11: 30$ & $11: 30$ & $11: 30$ & $11: 30$ & $11: 30$ & $11: 30$ & $11: 30$ \\
\hline $\begin{array}{l}7 \text { HTS Wire Cutting } \\
\text { \&Demoulding }\end{array}$ & 8 & $3: 25$ & $3: 25$ & $3: 48$ & $3: 36$ & $3: 52$ & $3: 46$ & $3: 45$ \\
\hline Total & 45 & $23: 55$ & $32: 38$ & $36: 38$ & $33: 54$ & 33:01 & $33: 17$ & $33: 54$ \\
\hline 8 Gap Time & & 00:00 & $5: 25$ & $2: 22$ & $4: 35$ & $6: 03$ & $5: 38$ & $4: 49$ \\
\hline 9 Total Time with Gaps & & $23: 55$ & 38:03 & 39:01 & $38: 28$ & 39:04 & $38: 55$ & $38: 42$ \\
\hline
\end{tabular}

\section{Simulation to Identify Bottlenecks}

Since sub process is complex, discrete event simulation was attempted for three-bed sleeper production process using ExtendSim software. The results of simulation is illustrated in Figure 6. Initially one unit of each resourcewas considered. The timing of activities on the different beds was varied and checked for minimum waiting time. It was found that for 1 nos. each of all the resources, HTS wire pulling on bed-2 had a waiting time of $3 \mathrm{hr} 45 \mathrm{~min}$, HTS wire pulling on bed-3 had a waiting time of $1 \mathrm{hr} 45 \mathrm{~min}$ and Concreting on bed- 3 had a waiting time of $2 \mathrm{hr} 15 \mathrm{~min}$. The total time was $37 \mathrm{hr} 15 \mathrm{~min}$. From the utilization of resources data, it was observed that the baffle machine has the highest utilization rate of $73.5 \%$.

The second simulation with 2 nos. of baffle machine and 1 nos. of all other resources completely eliminated idle time. The sleeper production $\mathrm{C} / \mathrm{T}$ reduced to $33 \mathrm{hrs} 15 \mathrm{~min}$ from $37 \mathrm{hr} 15 \mathrm{~min}$. However, baffle machine utilization was $38 \%$ with slight increase in utilization of other machines. The operations were optimization through method study which resulted into $3 \mathrm{hrs}$ reduction in $\mathrm{C} / \mathrm{T}$ of cleaning and insert fixing operation and 2.5 hours saving in HTS wire pulling operation. Thus, C/T for sleeper laying sub-process reduced to $27 \mathrm{hr} 45 \mathrm{~min}(33 \mathrm{hr} 15 \mathrm{~min}-3 \mathrm{hr}-2.5 \mathrm{hr})$ producing 1200 sleepers 1037 sleepers in 24 hours cycle using 3 bed system and additional baffle machine. Since, 9 beds system can produce 3113 beds in 24 hours cycle, C/T for 2500 sleeper production will be in 19 hrs. 


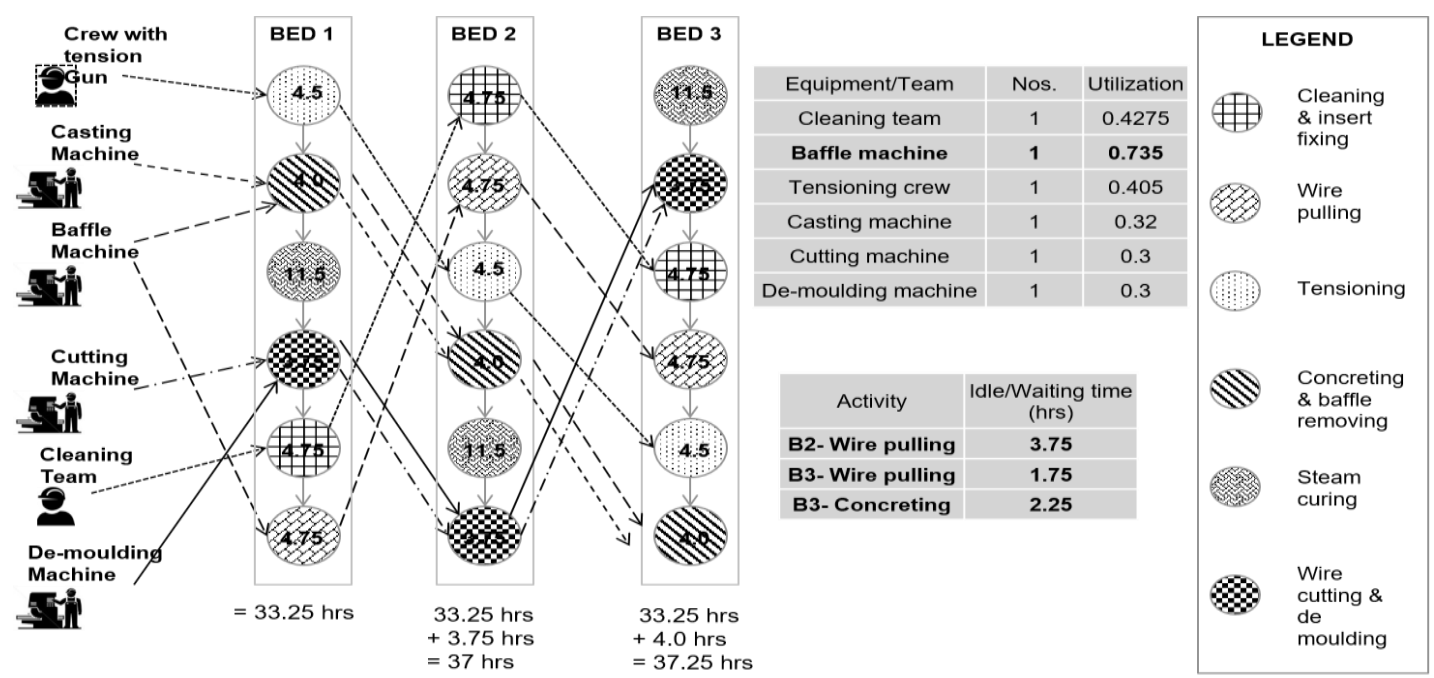

Figure 6: Simulation Trial 1

\section{RESULTS AND DISCUSSION}

As seen before, $\mathrm{C} / \mathrm{T}$ of sub processes/ operations can be reduced by additional allocation of resource or elimination of waste/flow activities. The initially planned $\mathrm{C} / \mathrm{T}$ for various sub processes/ operations along with revised C/T has been summarized in the Table 2.

\section{Track laying with Single rake system}

As per revised C/T, rail panel loading commenced at $0800 \mathrm{hrs}$ and ends at $1100 \mathrm{hrs}$. The sleeper loading commenced at $1100 \mathrm{hrs}$ and ends at $1600 \mathrm{hrs}$. Loaded rake starts at 1600 hrs and reach NTC location at $0200 \mathrm{hrs}$ next day. The NTC starts track laying at $0300 \mathrm{hrs}$ and empty rake returns for panel loading at $1800 \mathrm{hrs}$ day. Thus, despite higher rate of sleeper production, the $\mathrm{C} / \mathrm{T}$ for track laying remains $32 \mathrm{hrs}$. To overcome the problem two rake system can be used.

\section{Track laying with Two Rake system}

The two rakes system will reduce $\mathrm{C} / \mathrm{T}$ to $21 \mathrm{hrs}$ because $11 \mathrm{hrs}$ spent on connecting with NTC and track laying will happen in staggered manner as shown in Table 2. Considering maintenance period, NTC can work at the most 20 hrs in 24 hrs cycle. As shown in Table 2 , each operation/ sub-process will have two shifts in $24 \mathrm{hrs}$. The sleeper production system will have to work continuously and will require 14.5 sleeper beds to produce 5000 sleepers in 24 hrs cycle or approximately $23 \mathrm{hr}$ with 15 beds (i.e $5 \mathrm{x} 3$ beds). This type of arrangement will ensure $3 \mathrm{~km}$ track laying in 24 hours or $72 \mathrm{kms}$ in a month (i.e.26 days, less Sundays) against actual progress of $30 \mathrm{kms}$ per month.

Table 2: Process C/T with Single and Two Rake System

Sub process/
Process C/T (Hrs)

\section{Remarks}




\begin{tabular}{|c|c|c|c|c|c|}
\hline \multirow[t]{2}{*}{ Operation } & \multirow{2}{*}{$\begin{array}{l}\vec{D} \\
\frac{\mathbb{E}}{\mathbb{Z}}\end{array}$} & \multicolumn{3}{|c|}{ Revised C/T } & \\
\hline & & 这 & One Rake & Two Rake & \\
\hline A Track laying & 28 & 40 & 32 & $21 @$ & @ Timing staggered \\
\hline A1:Load rail panel & 4 & 3 & 3 & 3 & As per actual \\
\hline A2: Load sleepers & 6 & 11 & 5 & 5 & 2 Gantry used \\
\hline A3: Move rake to NTC & 5 & 10 & 8 & 8 & GPS system for tracking \\
\hline A4: Connect to NTC & 1 & 1 & 1 & Nil @ & \\
\hline A5: NTC operation & 8 & 10 & 10 & Nil @ & NTC lays $3.0 \mathrm{~km}$ in 24 cycle \\
\hline A6: Rake returns & 4 & 5 & 5 & 5 & As per actual \\
\hline B- Rail Panel production & 16 & 16 & 16 & $16^{*}$ & *Two shifts of $16 \mathrm{hrs}$ each \\
\hline C-Sleeper production & 30 & 47.3 & $19 \$$ & $21 \#$ & $\begin{array}{l}\text { \$9 sleeper beds required } \\
\text { \# } 15 \text { sleeper beds required }\end{array}$ \\
\hline
\end{tabular}

In the present study focus was on synchronization of $\mathrm{C} / \mathrm{T}$, thus waste reduction was limited to identification of issues causing inefficiencies and assessing approximate reduction in $\mathrm{C} / \mathrm{T}$. More improvement in $\mathrm{C} / \mathrm{T}$ may be feasible using lean tools and techniques (i.e VSM, Bigroom, etc). As seen in Table 1, all sub processes and operations finally have balanced over $\mathrm{C} / \mathrm{T}$ of $24 \mathrm{hrs}$ by having two shifts except sleeper production process which progresses continuously. The use of simulation was restricted to sleeper production sub process which was complex critical for process optimization. The impact of starting of sleeper production with a lead time, leapfrogging of depots and variable hauling time were not considered in the present study. These aspects may be explored in future works.

\section{SUMMARY AND CONCLUSIONS}

The problem associated with the part mechanization in construction industry was explained with the help of a case study wherein full benefit could not be achieved in the absence of synchronization among various sub processes and operations. A hierarchical framework was presented to analyze the flow process including supporting sub-processes and operations. Construction bottlenecks are eliminated by reducing $\mathrm{C} / \mathrm{T}$ of selected sub processes/ operations followed by synchronization of $\mathrm{C} / \mathrm{T}$ through allocation of additional resources and/ or elimination of waste using lean principles.

The solution framework was tested using data collected from ongoing automated railway track laying project. Initially the progress was $1.15 \mathrm{~km}$ per day against planned progress of $1.5 \mathrm{~km}$ per day. The sleeper production sub process emerged as the key sub process after analysis. The process was synchronised over $24 \mathrm{hrs}$ cycle by increased sleeper beds from 5 to 15 along with 5 additional baffle machines. Other resources were doubled by employing them in two shifts. These actions enhanced NTC productivity to 3 $\mathrm{km}$ per day or $72 \mathrm{~km}$ against actual progress of $30 \mathrm{~km}$ per month (i.e., 24 working days).

The study revealed that lack of synchronization in a feeding process create construction bottlenecks and restrict continuous flow of input material to the pull 
activities. Adding resources or waste reduction does reduce the $\mathrm{C} / \mathrm{T}$ but may not enhance the overall rate of progress if the flow is not balanced, rather shift the location of bottlenecks. The proposed framework, offers systematic approach needed to identify and progressively synchronize the $\mathrm{C} / \mathrm{T}$ till required rate of progress is achieved.

\section{REFERENCES}

Alzraiee, H., Zayed, T., \& Moselhi, O. (2015). "Dynamic planning of construction activities using hybrid simulation". Automation in Construction, 49, 176-192.

Ballard, G., \& Howell, G. (1994). Implementing lean construction: stabilizing work flow. Lean construction, 101-110.

Ballard, G., \&Tommelein, I. (1999). "1 Aiming for Continuous Flow”.

Bertelsen, S., Koskela, L., Henrich, G., \&Rooke, J. (2006). "Critical flow-towards a construction flow theory".IGLC 2006.

Binninger, M., Dlouhy, J., Oprach, S. and Haghsheno S. (2016)."Methods for Production Levelling - Transfer from Lean Production to Lean Construction". IGLC 2016.

Diekmann, James E., et al. "Application of lean manufacturing principles to construction." Boulder, CO, Construction Industry Institute 191, 2004.

Koskela, L. (2000). "An exploration towards a production theory and its application to construction".VTT Technical Research Centre of Finland.

Oglesby, C. H., Parker, H.W., and Gregory, A.H., (1989). "Productivity improvement in construction",McGraw-Hill, New York.

Pawan Pandey, J. Uma Maheswari and ShailaMaheswari. (2017). "Clearing Construction Bottleneck through Flow Process Design”. ILCC-2017, Chennai, India.

Stake, R. E. (1995). "The art of case study research", Thousand Oaks: Sage.

Hopp, W. J., and Spearman, M. L. (2001). "Factory physics: foundations of manufacturing management." Irwin/McGraw-Hill, Boston. 